\title{
PUBLIC AWARENESS AND CONSUMPTION OF ENVIRONMENTALLY FRIENDLY PRODUCTS: IMPLCATIONS FOR GREEN MARKETING MANAGEMENT
}

Weng Marc Lim, School of Business, Monash University

Ding Hooi Ting, School of Business, Monash University

Chee Yue Wong, School of Business, Monash University

Jia Jun Mah, School of Business, Monash University

$\underline{\text { dx.doi.org/10.18374/IJSM-13-2.5 }}$

\begin{abstract}
Green marketing strategies are often ineffective as inconsistencies exist between the strategies and the state of green consumerism in the marketed culture. While most studies in the literature have provided a comprehensive portrayal on the states of green consciousness of American and European consumers, the understanding of such states of consumers from other parts of the world remains infertile. Marketing literature has suggested that undifferentiated marketing strategies become less relevant when marketing offerings across cultures. Various multi-nationals and governmental associations have call for more in-depth understanding on consumer awareness and perception on green issues and offerings across culture, particularly in rapidly growing Asian economies. This study attempts to address these issues by examining public awareness and consumption of environmentally friendly products in an Asian country - Malaysia. Qualitative individual interviews are conducted to obtain an in-depth understand of consumer environmental consciousness and behaviour. Findings suggest that consumers are increasingly concerned about the environment. However, there is a value-action gap between the beliefs of consumers and their actual purchase and consumption of environmentally friendly products. Relevant implications and recommendations are provided.
\end{abstract}

Keywords: Green Marketing, Public Awareness, Consumption, Environmentally Friendly Products. 